\title{
The Relationship between Ethical Climate and Job Satisfaction among High School Teachers of Saveh City
}

\author{
Ensiyeh Torabian \\ Department of Educational Management, College of Human Science \\ Saveh Branch, Islamic Azad University, Saveh, Iran
}

Amirhossein Mohammad Davoudi (Corresponding author)

Member of Faculty in Department of Educational Management

College of Human Science, Saveh Branch, Islamic Azad University, Saveh, Iran

Email: adavoudi838@yahoo.com

Received: June 14, 2016 Accepted: July 16, 2016 Published: July 28, 2016

doi:10.5296/ijld.v6i3.9796 URL: http://dx.doi.org/10.5296/ ijld.v6i3.9796

\begin{abstract}
The goal of this research was to study the relationship between ethical climate and job satisfaction among high school teachers of Saveh city in 2015. It was a theoretical study regarding objectives and descriptive-correlation in relation to data collection. The study population consisted of 300 high school teachers of Saveh city in which 152 people were selected as the sample volume by Cochran formula and stratified random sampling. The data collection method was based on 21-question standard ethical climate questionnaires according to the study of Wang and Sieh (2012) and 15-question job satisfaction questionnaire based on the study of Williams and Anderson (1991) and these were based on Likert scale. Cronbach's alpha was used to calculate the reliability of the questionnaire and it was higher than 0.7 for all questionnaires $(0.758$ for ethical climate and 0.918 for job satisfaction). Also, the content validity was employed to evaluate the validity of the questionnaire. For this purpose, the questionnaires were approved by the professors and experts in this field. Analyzing the data extracted from the questionnaire were performed by SPSS software in two parts of descriptive and inferential (correlation and multivariate regression). The results from correlation test showed that there is a significant relationship between ethical climate and its 5 dimensions namely instrumental climate, caring climate, law and rules climate, regulation climate, and independence climate and job satisfaction of high school teachers with 0.01 level of significance. Moreover, the results of analyzing the
\end{abstract}


regression indicated that among 5 dimensions of ethical climate, only instrumental and regulation climate can predict job satisfaction in high school teachers of Saveh city.

Keywords: Ethical climate, Job satisfaction, Instrumental climate, Regulation climate

\section{Introduction}

Today, human resource is known as the main capital of an organization and educational institute and job satisfaction are one of the most important factors to maintaining such forces. Therefore, one of the biggest or perhaps one of the most controversial concepts that gain theoretical and fundamental efforts on one hand, and on the other hand, attracts much attention in all levels of management and human resources of an organization, is job satisfaction. On the one hand, this structure has a basic role in the development and improvement of an organization as well as workforce health and on the other hand, job satisfaction, in addition to numerous and sometimes complex definition and conceptualization, is the intersection as well as common structure of many scientific fields such as education, psychology, management, sociology, economics, and even politics (Davoudi, Bahadori, Mirzajani, 2012).

Job satisfaction is the most studied variable in both research and practical aspects. There are numerous reasons to consider this working attitude. First, the organizations would like to evaluate the current situation of their employees regarding job satisfaction and second, many types of research have carried out to evaluate the job satisfaction of the employees. Various countries studied the status of job satisfaction in the business system and this issue has been investigated from different points of views. The job satisfaction has always been and will be an issue in the organizations. So that until 1980, more than 4000 papers have published in this area (Torkaman and Abedi, 2009).

Spector (1997) believes that job satisfaction is the view that indicates how people are generally feeling about their jobs. Job satisfaction has five areas including satisfaction at work, the satisfaction of the supervision, satisfaction of colleagues, satisfaction of the salary, and satisfaction of the promotion. Overall job satisfaction forms from the sum of these areas. Therefore, it can be said that one of the factors that are effective in forming the communications inside an organization and also has a major impact on the employee's circumstances is ethical climate (Najafi et al., 2010). Victor and Cullen in 1987 defined ethical climate as the common perceptions about what is right ethically and how one should face the ethical issues in the organization. They identify five dimensions of ethical climate namely (instrumental, caring, regulation, law, and independence). The research results show that employees with higher job satisfaction are in a better physical and mental body situation. Also, the results of studies have revealed that there is a negative relationship between job satisfaction and the absence of staff so that increasing job satisfaction lead to a decrease in work absenteeism (Asghari, Khalegh Doust, Asgari, Kazem Nezhad, 2010).

The educational system has a major role in the future of our country. The teachers have the main role in educating and training the students in this organization and they have a tough job. 
Since they are in the direct contact with the process of teaching and learning, in the case of academic failure and unmotivated students, they feel more job pressure and their mental health could be in danger (Khayatian et al., 2014).

Since the educational system is an effective factor in growth and development of the countries, this organization should be paid special attention. The basic elements of this system, teachers in all academic courses namely, elementary, secondary, and high school should be paid special attention, because if teachers suffer from various physical and mental diseases during their career, they would indeed lose job satisfaction and the educational system faces a serious problem regarding the communicating with its major elements i.e. the teachers and students or even other constituting elements and consequently it will not perform in the direction of its specific objects (Torkaman and Abedi, 2009). On the other hand, today, due to life's condition, the difficulties in personal and work life are intertwined in a way that people devote significant time to work in order to meet their material needs in which its consequences would be occupational burnout, reluctance, etc. The studies show that job stresses limit the attention of the employees and thus decrease their work capacity. Also, the employees who experience more job stresses will have a less organizational commitment (Na'aami and Zargar, 2008). Due to the direct contact of teachers and students and the quality of this contact that can lead to promotion in the quality of education, paying attention to teachers' job satisfaction is necessary to improve the educational performance. Moreover, the main cause of studying the high school is the complexion and additional difficulties among the teachers of the high school. According to the research about job satisfaction, the author believes that the solution to this matter lays in the ethical climate in high schools. Hence, this question will be raised that what is the relationship between ethical climate and the job satisfaction among high school teachers of Saveh city?

Based on the abovementioned question, the research assumptions are as follows:

- There is a relationship between ethical climate and job satisfaction of high school teachers.

- There is a relationship between instrumental climate and job satisfaction of high school teachers.

- There is a relationship between caring climate and job satisfaction of high school teachers.

- There is a relationship between laws and rules climate and job satisfaction of high school teachers.

- There is a relationship between regulation climate and job satisfaction of high school teachers.

- There is a relationship between independence climate and job satisfaction of high school teachers.

In the study of Williams and Anderson (1991), the job satisfaction was evaluated. The ethical climate is related to jab satisfaction though five dimensions including instrumental, caring, 
independence, laws and rules, and regulations. The job satisfaction is considered as the criterion variable in the study, and the ethical climate and its dimensions are known as the research predictor variables. Accordingly, the research theoretical framework formed as follows:

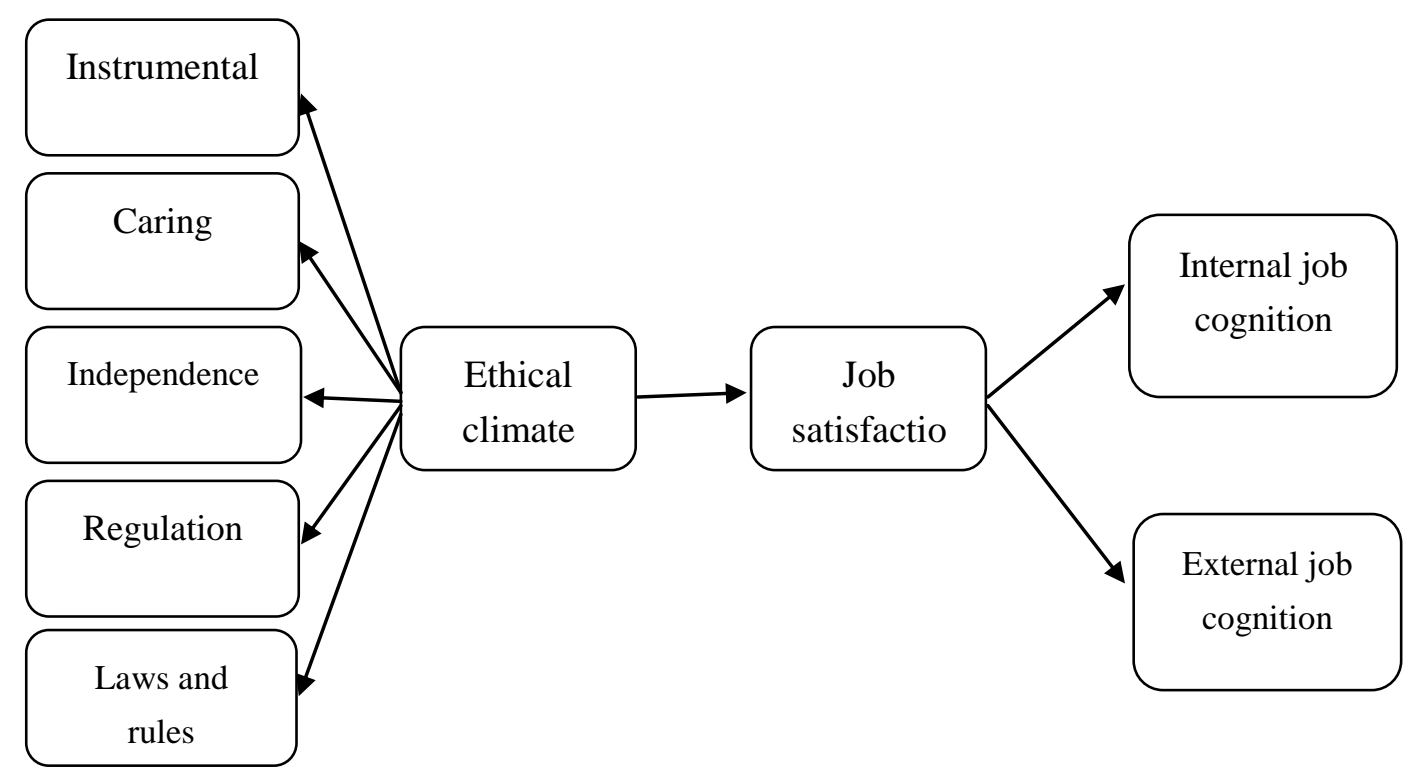

Figure 1. The conceptual model of the research (ref. Wang and Sieh (2012) and Williams and Anderson (1991))

\section{Methodology}

Since the present research seeks to find the relationship between ethical climate and job satisfaction from the high school teachers' point of view, the research method is descriptive and correlation. Also, it is a theoretical study regarding the goal because the results will be used in the study population. The study population consisted of all high school teachers of Saveh city which estimated to be 300 people ( 80 men and 220 women) based on information extracted from the human resource in the education system of Saveh city in 2015. The Cochran formula and stratified random sampling were used to select 152 people (111 women and 41 men) as the sample volume. The data were collected by a survival method using questionnaire tool in this study.

The research questionnaire includes two parts. First, there are some questions related to the general profile of the subjects, and then, there are 36 questions related to two structures of ethical climate and job satisfaction (21 questions related to ethical climate and 15 questions related to job satisfaction). The questions related to ethical climate are designed using Wang and Sieh questionnaire (2012). This is a 21-question questionnaire which is based on 5-point Likert scale (very low $=1$, low $=2$, medium $=3$, much $=4$, very much $=5$ ). This structure studies 5 dimensions of instrumental, caring, independence, laws and rules, and regulations among the high school teachers of Saveh city. Moreover, the standard questionnaire of Williams and 


\section{Macrothink}

International Journal of Learning and Development

ISSN 2164-4063

2016, Vol. 6, No. 3

Anderson (1991) was used to provide the job satisfaction questionnaire. This questionnaire contains 15 questions which are designed based on 5-point Likert scale (very low=1, low=2, medium $=3$, much $=4$, very much $=5$ ). This structure evaluates two dimensions of internal and external job cognition in high school teachers of Saveh city. The table below shows that each question in questionnaire explains which variables.

Table 1. The distribution of questions for each variable in the study

\begin{tabular}{|c|c|c|c|c|}
\hline \multirow{2}{*}{ Aspect } & Dimension & $\begin{array}{c}\text { Cronbach's } \\
\text { alpha }\end{array}$ & $\begin{array}{c}\text { Items related to } \\
\text { each variable }\end{array}$ & Number of items \\
\hline \multirow{3}{*}{ Ethical } & Instrumental & 0.736 & $16-21$ & 6 \\
\hline \multirow{2}{*}{ climate } & Caring & 0.838 & $22-25$ & 4 \\
\cline { 2 - 5 } & Independence & 0.779 & $34-36$ & 3 \\
\cline { 2 - 5 } & Regulation & 0.794 & $30-33$ & 4 \\
\hline \multirow{2}{*}{$\begin{array}{c}\text { Job } \\
\text { satisfaction }\end{array}$} & Internal job cognition & 0.836 & $26-29$ & 8 \\
\cline { 2 - 5 } & External job cognition & 0.879 & $1-2-3-6-7-8-11-12$ & 7 \\
\hline
\end{tabular}

In this research, to verify the validity of the questionnaire, the face and content validity methods were employed. The questionnaires were handed out to experts and specialists in this field and the face validity was verified. Since the questionnaire designed based on Likert scale, Cronbach's alpha method is the most suitable method to calculate the reliability. The values of Cronbach's alpha for two main structure and their dimensions in which they were calculated by pre-test to measure the reliability $(\mathrm{N}=27)$ are shown in the table above. As it can be observed from the table, the value of Cronbach's alpha is higher than 0.7 for all dimensions, therefore, it can be concluded that the questionnaire has the required reliability.

Statistical methods were used in two ways of descriptive and inferential. Testing research assumptions were carried out in inferential part using SPSS software under correlation and regression tests.

\section{Findings}

In this section, first, we statistically describe the sample and study variables and then evaluate the research assumptions by Pearson's correlation method and multivariate regression. It is worth mentioning that 9 questionnaire eliminated due to lack of information and the study population reduced to 143 people.

\subsection{Descriptive Statistics of Subjects}

Table below summarizes the demographic aspects of sample and also provide mean and standard deviation of the variables. 


\section{Ml Macrothink}

International Journal of Learning and Development

ISSN 2164-4063 2016, Vol. 6, No. 3

Table 2- Demographic information of the sample

\begin{tabular}{|c|c|c|c|c|c|c|c|}
\hline Variable & Class & Frequency & Percentage & Variable & Dimension & S.D. & Mean \\
\hline \multirow{2}{*}{ Gender } & Woman & 103 & \multirow{2}{*}{28} & \multirow{2}{*}{$\begin{array}{c}\text { Job } \\
\text { satisfaction }\end{array}$} & \multirow{2}{*}{$\begin{array}{c}\text { Job } \\
\text { satisfaction }\end{array}$} & \multirow[b]{2}{*}{8.2} & \multirow[b]{2}{*}{54.91} \\
\hline & Man & 40 & & & & & \\
\hline \multirow{6}{*}{$\begin{array}{l}\text { Level of } \\
\text { education }\end{array}$} & \multirow[t]{2}{*}{ Graduate } & \multirow[t]{2}{*}{98} & \multirow[t]{2}{*}{68.5} & \multirow{6}{*}{$\begin{array}{l}\text { Ethical } \\
\text { climate }\end{array}$} & Instrumental & 0.86 & 2.4 \\
\hline & & & & & Caring & 0.82 & 2.99 \\
\hline & \multirow{4}{*}{ Post-graduate } & \multirow{4}{*}{45} & \multirow{4}{*}{31.5} & & $\begin{array}{c}\text { Laws and } \\
\text { rules }\end{array}$ & 0.75 & 3.16 \\
\hline & & & & & Regulation & 0.77 & 3.88 \\
\hline & & & & & Independence & 0.91 & 3.72 \\
\hline & & & & & Total & 0.52 & 3.13 \\
\hline
\end{tabular}

The results of the study in descriptive statistics of subjects (characteristics of participants) which can be seen in the table above, showed that the highest percentage of participants were women in with the age ranging 24 to 58 with the average of 40.38 years old (the highest frequency belongs to 45 years old teachers), who were university graduated, and they had 2 to 34 years of job experiences. The mean and the standard deviation of job experience among the subjects were 18.25 and 8.4 , respectively.

\subsection{Normal distribution of the data}

Regarding testing the assumptions, the quantitative variables such as correlation tests and regression, the default for the researcher is that quantitative data follow a normal distribution. To evaluate the normal distribution of the data, Shapiro-Wilk test was employed in this study. The results are given in the table below:

Table 3- The summarized results of Shapiro-Wilk test $(n=143)$

\begin{tabular}{|c|c|c|c|}
\hline Variables & Ethical climate & Test statistics & Level of significance \\
\hline \multirow{3}{*}{ Ethical climate } & Instrumental & 0.969 & 0.01 \\
\cline { 2 - 4 } & Caring & 0.966 & 0.01 \\
\cline { 2 - 4 } & Laws and rules & 0.982 & 0.06 \\
\cline { 2 - 4 } & Regulation & 0.954 & 0.01 \\
\hline \multicolumn{2}{|c|}{ Job satisfaction } & 0.941 & 0.01 \\
\hline
\end{tabular}

According to the table above, the level of significance is higher than 0.05 for "Laws and rules climate"; in other words, the data related to "laws and rules" follow a normal distribution. While the distribution is not symmetrical for "instrumental climate", "caring climate", "regulation climate", and "independence climate". Furthermore, the scores of subjects follow the normal distribution in job satisfaction variable.

\subsection{Testing Research Assumptions}

In this section, based on the nature of research variables, the $4^{\text {th }}, 2^{\text {nd }}, 1^{\text {st }}$, and $5^{\text {th }}$ secondary 
assumptions tested with Spearman correlation coefficient, and the $3^{\text {rd }}$ secondary assumption tested with Pearson correlation coefficient and the main assumptions were tested by multivariate regression.

- There is a relationship between instrumental climate and job satisfaction in high school teachers.

- There is a relationship between caring climate and job satisfaction in high school teachers.

- There is a relationship between laws and rules climate and job satisfaction in high school teachers.

- There is a relationship between regulation climate and job satisfaction in high school teachers.

- There is a relationship between independence climate and job satisfaction in high school teachers.

The results of the abovementioned assumptions were reported in correlation matrix between ethical climate dimensions and job satisfaction.

Table 4- The correlation matrix between ethical climate dimensions and job satisfaction $(n=143)$

\begin{tabular}{|c|c|c|}
\hline Ethical climate dimensions & Correlation coefficient & Level of significance \\
\hline Instrumental climate & -0.309 & 0.01 \\
\hline Caring climate & 0.408 & 0.01 \\
\hline Laws and rules climate & 0.358 & 0.01 \\
\hline Regulation climate & 0.470 & 0.01 \\
\hline Independence climate & 0.438 & 0.01 \\
\hline
\end{tabular}

According to the table above, the following results were obtained (the correlation coefficient can be seen in the table):

- There is a negative and significant relationship between the instrumental climate of schools and job satisfaction in teachers i.e. increasing the instrumental climate leads to decreasing the job satisfaction.

- There is a positive and significant relationship between the caring climate of schools and job satisfaction of teachers i.e. increasing the caring climate in schools causes job satisfaction among teachers.

- There is a positive and significant relationship between laws and rules climate in schools and jab satisfaction of teachers. More correctly, increasing laws and rules climate in schools leads to job satisfaction of teachers.

- There is a positive and significant relationship between regulation climate in schools and job satisfaction of teacher. This means that with an increase in caring climate in schools, the job satisfaction gets higher among the teachers. 
- There is a positive and significant relationship between independence climate and job satisfaction of the teachers. In other words, the more the independence climate, the higher the job satisfaction of teachers.

\section{There is relationship between ethical climate and job satisfaction of high school teachers.}

The above assumption was evaluated by stepwise multiple regression tests; but before the calculations, these test hypotheses were examined. It is worth mentioning that in this stage, 3 outlier data were identified and the regression test calculated by 140 data. The findings have shown that the hypotheses of the independence of the error, scatter diagram, and normality of the error term are verified and multiple regression tests can be used. The table below summarize the regression test results for studying the relationship between ethical climate and job satisfaction.

Table 5- the summarized data of regression test for studying the relationship between ethical climate and job satisfaction.

\begin{tabular}{|c|c|c|c|c|c|c|}
\hline Model & Predictor variables & $\begin{array}{c}\text { Correlation } \\
\text { coefficient }\end{array}$ & $\begin{array}{c}\text { The square of } \\
\text { correlation } \\
\text { coefficient }\end{array}$ & $\begin{array}{c}\text { Normalized } \\
\text { correlation }\end{array}$ & $\Delta \boldsymbol{R}^{2}$ & $\begin{array}{c}\text { Level of } \\
\text { significance }\end{array}$ \\
\hline 1 & Regulation climate & 0.505 & 0.255 & 0.250 & 0.255 & 0.01 \\
\hline 2 & $\begin{array}{c}\text { Regulation climate } \\
\text { Caring climate }\end{array}$ & 0.582 & 0.339 & 0.330 & 0.084 & 0.01 \\
\hline 3 & $\begin{array}{c}\text { Regulation climate } \\
\text { Caring climate } \\
\text { Instrumental climate }\end{array}$ & 0.604 & 0.365 & 0.351 & 0.026 & 0.02 \\
\hline
\end{tabular}

The criterion variable: job satisfaction

According to the table above, among 5 predictor variable (instrumental climate, caring climate, law climate, regulation climate, and independence climate), only three variable (regulation climate, caring climate, and instrumental climate) entered the regression model, so that the relationship among these three variable and "job satisfaction" estimated to be 0.604; in other words, regulation, caring and instrumental climates, explain approximately 36.5 percent of job satisfaction variations $(\mathrm{R} 2=0.365)$; and regulation climate has the most effective role with 25.5 percent. The share of caring climate and instrumental climate has been reduced to 8.4 and 2.6, respectively. As it can be observed, the independence and laws and rules climate has been eliminated from the model; this means that they lost their role in explaining job satisfaction. Furthermore, the findings have shown that the calculations related to F statistics, squared multiple correlations is significant at the level of $0.01(\mathrm{p}=0.01 ; 136$ and $\mathrm{df}=3, \mathrm{~F}=26.1$ ). The next output of the computer indicates regression coefficient analysis. 


\section{MInstitute Macrothink $_{\text {Int }}$}

International Journal of Learning and Development

ISSN 2164-4063

2016, Vol. 6, No. 3

Table 6- The dimension correlations of ethical climate in schools in predicting job satisfaction of teachers

\begin{tabular}{|c|c|c|c|c|c|c|}
\hline $\begin{array}{c}\text { Variables } \\
\text { entered the } \\
\text { model }\end{array}$ & Model & B & SE & (Beta) & T & $\begin{array}{c}\text { Level of } \\
\text { significance }\end{array}$ \\
\hline $\begin{array}{c}\text { Regulation } \\
\text { climate }\end{array}$ & $\begin{array}{c}\text { Intercept } \\
\text { Variable } \\
\text { coefficient }\end{array}$ & 34.9 & 3.7 & & 9.4 & 0.01 \\
\hline $\begin{array}{c}\text { Caring } \\
\text { climate }\end{array}$ & $\begin{array}{c}\text { Variable } \\
\text { coefficient }\end{array}$ & 0.68 & 0.170 & 0.285 & 4 & 0.01 \\
\hline $\begin{array}{c}\text { Instrumental } \\
\text { climate }\end{array}$ & $\begin{array}{c}\text { Variable } \\
\text { coefficient }\end{array}$ & -0.241 & 0.102 & -0.166 & -2.4 & 0.02 \\
\hline
\end{tabular}

The criterion variable: job satisfaction

According to the data in the table above, the regression equation can be written as follows:

Predicted job satisfaction $(\mathrm{Y})=34.96+1.01($ Regulation climate $)+0.676($ Caring climate $)-$ 0.241(instrumental climate)

Based on the above regression model, it can be said that with one unit increase in regulation and caring climate in high schools of Saveh city, the job satisfaction will go up with 1.01 and 0.676 units and with one unit increase in instrumental climate in schools, the job satisfaction of the teachers decreases to 0.241 units.

\section{Conclusion and Recommendations}

In this section, based on the literature review and the results from analyses, the assumptions will be explained and some recommendations will be presented. The results from analyzing the data have shown that there is a relationship between ethical climate and job satisfaction in high school teachers.

Ethical climate emphasizes on employees perception of right behaviors. Accordingly, the existence of ethical climate led them to accepted social, group, and individual norms which in return, create an ethical climate in the work environment. However, this should be noted that if there were no codes and values to direct the ethical behavior, the norms are not sufficient for creating an ethical climate, because they are not always intellectual and moral. Therefore, in addition to norms, procedures and policies should be created in the organizations for ethical behavior and moralization and their implementation should be emphasized. In such a condition, the working atmosphere moves toward moralization and the result will be an ethical climate in the organization. Institutionalization of ethical climate in an organization leads to justification and consequently commitment in the organization. When organizational justice observed by the employees and they would be committed to the organization, the employees would be satisfied with their job and organization and perform better.

In the instrumental climate, the members of the organization seek to acquire personal gain rather than concerning with others profit and the existing norms and expectations, motivate 
moral decision-making from a selfish point of view in a way that personal interests take precedence. One's interests could not be in accordance with the organization interests and thus, result in negative consequences for the organization. Since the purpose of an individual takes precedence to the purpose of the organization, the organizational discipline could be disrupted and it also promotes the culture of pursuing personal interests in an organization that can endanger the survival of an organization. On the other hand, when the instrumental climate is governed by an organization, because of the lack of alignment in employee's goals, some kind of conflict appears in the organization which results in reducing job satisfaction among employees. Thus, the instrumental climate has an inverse relationship with job satisfaction of the employees.

In the caring climate, the organization's employees have an interest in each other's well-being and consider all affected people when making a decision. In such a climate, people understand that they should consider other people's well-being. The existence of such a climate can promote collaboration and interactions among employees because they all believe that they support one another. The result of such an attention and perceiving the collective support as well as increasing interactions can be seen in job satisfaction of the employees. Ethical climate based on caring approach can lead to a positive and attitude and impressions from one's job content, in a way that the employees feel satisfied with working in an environment that they are being supported doing their jobs and also they are considered in the process of decision making.

The laws and rules climate is based on understanding the organizational support from fundamental decisions according to external laws such as legislation, religion or occupational and professional laws. In such a climate, the decision making is based on ethical climate, and it considers as a judgment rather than a consequence. The ethic fundamentals involve institutional and organizational norms and religious beliefs. In fact, the ethic fundamentals guide the decisions and help the decision-makers to make decisions based on ethics. Hence, it can lead to ethical decisions, but since the decisions are judged, this can consider as a positive or negative issue. This can indicate why there is no relationship between laws and regulations and job satisfaction.

The procedures and regulations of an organization empirically appear in regulation climate. The organizational decisions lead by a set strong and pervasive of regional regulations or standards. Since the organizational regulations are significantly clear, so the decisions are judged less their results can be observed better. Adhesion to regulation climate can develop justice and discipline in the organization and would provide employees' satisfaction because the decisions are mainly based on the regulations and are less likely to provide personal interest for an individual or a group in the organization. So it leads to less dissatisfaction.

In the independence climate, the members of the organization make the decisions independently and according to their perceptions of right or wrong. In such a climate, the decisions are making based on ethical consequences and with an emphasis on the ethical beliefs with minimum consideration of external forces and effects on the ethical issues. In this climate, ethnic and religious culture are very effective because national and religious 
beliefs have a strong emphasis on some actions being right or wrong, so that some communications are perfectly normal and right in a western organization, while they could consider as anomalies in Muslim country due to religious beliefs. Moreover, in addition to national and religious beliefs, personal attitudes can be effective in considering an action right or wrong. Thus, the independence climate which is based on personal judgment can be considered positive or negative. The differences in the views of employees can lead to different perceptions in an organization which in turn can cause satisfaction or dissatisfaction of the employees.

In line with the results of this research, Elsie and Alpine (2009) showed that the effect of social responsibility on job satisfaction is significant. The results indicate that there is a simple relationship between job satisfaction and psychological well-being. They showed that there is a relationship between ethical climate and organizational commitment. Montakhab Yeganeh et al. (2013) exhibited that the ethical climate has an impact on organizational commitment, Arshadi and Piriaee (2014) showed that Islamic work ethics have a positive relationship with job performance and job satisfaction, Ghadiri et al. (2013) indicated that each one of five dimensions of ethical climate have a connection with organizational commitment, job satisfaction and turnover intentions, Rahim Nia and Nikkhah Farahani (2011), verified the effect of ethical climate in organization on organizational identity, Nadi and Hazeghi (2011) verified the impact of ethical climate on job satisfaction of employees, Najafi et al. (2010) believed that there is a significant relationship between personal interest, group interest, social responsibility and professional laws with job satisfaction which is consistent with the presented results.

Since the results have shown that there is a significant relationship between ethical climate and job satisfaction of high school teachers of Saveh city, the following recommendations will be presented:

5. The managers arrange some monthly unofficial friendly meetings to know the needs and interests of their employees. The employees were able to speak about their problems and the managers consider them in the process of decision making because it can establish some type of convergence in the goals of the organization and the aims of individuals.

6. According to behavioral characteristics and maturity level of the organization, the managers have supportive and caring behaviors toward their employees and encourage this behavior among them to promote caring climate.

7. The managers in the educational system have more attention to establishing clear regulations and ethical procedures; these increase the justice in the whole system and in addition to promoting ethical climate, the employees understand this justice in a more sensible way.

\section{Reference}

Arshadi, N. Piriaee, S. (2014). The relationship between Islamic work ethic and job 
performance, job satisfaction and turnover intentions. Journal of Islamic management. Year 20. No. 22. Issue 1, p 213.

Asghari, E. Khalegh Doust, T. Asgari, F. Kazem Nezhad, E. (2010). The study of effective factors in job satisfaction of nurses. Journal of School of Nursing and Midwifery, Guilan Province. Year 20. Issue 64. P 1-7.

Torkaman, F. Abedi, S.M. (2009). Identifying effective factors in job satisfaction of teachers. Journal of psychological research. Year 1. No. 4. P 38-48.

Khayyatan, F. Ahadi, H. Kamkar, M. Nafisi, Gh. (2014). Estimating the job satisfaction of the teachers using dimensions of job perfectionism. Journal of Knowledge and Research in Applied Psychology. Year 15. Issue 58. P 48-57.

Davoudi, H. Bahari, F. Mirzajani, S.M. (2012). The relationship between organizational culture and job motivation with job satisfaction of teachers. Journal of Occupational and Organizational Consulting. Year 4. No. 4. Issue 13. P 127-139.

Rahim Nia, F. Nikkhah Farkhani, Z. (2011). The effect of ethical climate of an organization on organizational identity and turnover intents of sellers. Journal of Ethics in Science and Technology. Year 6. Issue 4. P 1-11.

Ghadiri, M. Bashlideh, K. Hashemi, S.E. Moshkelati, F. (2013). The relationship between ethical climate and job satisfaction, organizational commitment and turnover intentions. Journal of Ethics in Science and Technology. Year 8. Issue 3. P 54.

Montakhab Yeganeh, M. Arshadi, N. Baharloo, M. Ahmadi Chagani, S. (2013). The relationship between ethical organizational climate, leader-member exchange and perceived external prestige with organizational commitment. Journal of Social Psychology. Year 8. No. 28. P 61-73.

Nadi, M.A. and Hazeghi, F. (2011). Pattern detection of the relationship between structural equations between ethical climate, job satisfaction and organizational commitment and turnover intention in employees in private hospitals in Shiraz. Health Information Management. Year 8. Issue 5. P 699-708.

Najafi, M. Karimi, M. Ghahramani Fard, A. Rezvani, S.M. (2009). Studying the relationship between ethical climate and job satisfaction among employees in educational system of Isfahan. New educational approaches. Year 5. Issue 2. P 1-22.

Na'aami, A. and Zargar, Y. (2008). Identifying job stressing factors and studying the relationship between these factors and job satisfaction in the employees of an industrial company. Psychological studies. Year 4. Issue 1. P 9-30. S

Wang, Y. D., \& Hsieh, H. H. (2012). Toward a better understanding of the link between ethical climate and job satisfaction: A Multilevel Analysis. Journal of business ethics, 105(4), 535-545.

Willams, J., \& Anderson, S. E. (1991). Job satisfaction and organizational. Journal of Applied 
Psychology, 78, 538-557.

Elci, M. and Alpkan, L. (2009). The impact of perceived organizational ethical climate on work satisfaction. Journal of Business Ethics. 84: 297-311.

\section{Copyright Disclaimer}

Copyright for this article is retained by the author(s), with first publication rights granted to the journal.

This is an open-access article distributed under the terms and conditions of the Creative Commons Attribution license (http://creativecommons.org/licenses/by/3.0/). 